\title{
Promoting Patient-oriented Medical Services: The Perceptions of Nurses toward Patient Safety Culture
}

\author{
Chih-Hsuan HUANG ${ }^{1,2, a}$, Li-Xin ZENG ${ }^{3,4, b}$, Hsin-Hung WU ${ }^{5,6, c}$, \\ Yii-Ching LEE ${ }^{5,6, d}$ and $\mathrm{Li} \mathrm{LI}^{7, e,{ }^{*}}$
}

${ }^{1}$ School of Business Administration, Hubei University of Economics, Wuhan City, China

${ }^{2}$ Institute for Development of Cross-Strait Small and Medium Enterprise, Hubei University of Economics, Wuhan City, China

${ }^{3}$ School of Business Administration, Hubei University of Economics, Wuhan City, China

${ }^{4}$ Department of Business Administration, National Changhua University of Education, Changhua, Taiwan

\author{
${ }^{5}$ Department of Health Business Administration, Hung Kuang University, Taichung City, Taiwan \\ ${ }^{6}$ School of Health Policy and Management, Chung Shan Medical University, Taichung City, Taiwan \\ ${ }^{7}$ College of Law \& Business of Hubei University of Economics, Wuhan City, China \\ atititacer@hbue.edu.cn, b878465448@qq.com, ${ }^{c}$ hhwu@cc.ncue.edu.tw, dyiiching.lee@gmail.com, \\ 'Lisat23@163.com \\ ${ }^{*}$ Corresponding author
}

Keywords: Patient safety culture, Safety attitudes questionnaire, Medical service.

\begin{abstract}
How to provide a patient-oriented medical service in hospitals has been emerged as an essential issue in China. The current study aims to provide implementations for hospital managers to enhance medical quality by investigating the perceptions of nurses regarding patient safety culture. Sexton et al. [7]'s safety attitudes questionnaire (SAQ) is used to assess the patient safety culture of nurses in a Grade III Level A hospital in China. The results illustrate that working conditions are essential components to establish a good atmosphere of patent-oriented medical service. Furthermore, the status of pressure perceived by nurses should not be ignored to reduce medical errors and malpractice during the medical procedures.
\end{abstract}

\section{Introduction}

The 19th National Congress of the Communist Party of China has emphasized the improvement of healthcare system to provide a patient-oriented medicial services in hospitals in China. Studies have stated that the importance of patient safety culture for benefiting healthcare organizations. For example, Lee et al. [1] pointed out that hospital staffs are more likely to work as a team if hospital management considers patient safety culture as one of priorities in improving medical services and quality. Huang et al. [2] also indicated that the stronger the atmosphere of patient safety create, the more job satisfaction hospital staffs perceive. Normally, nurses are regarded as core staffs in a hospital to contact with patients directly. It is critically important to recognize nurses' attitudes toward patient safety in healthcare organizations in order to enhancing medical services and competitive advantages in medical industry.

\section{Literature Review}

The establishment of patient safety culture for healthcare organizations has been considered an essential issue to improve medical services and competitive advantages in medical industry [2,3]. Patient safety culture represents medical staffs' beliefs and values that seek to minimize patient harm during the medical procedure [4]. Many studies suggest that monitoring nurses' perceptions of patient safety can help healthcare institutions to organize appropriate implements for reducing adverse medical events $[5,6]$. 
Safety attitudes questionnaire (SAQ) developed by Sexton et al. [7] has been widely used to identify the attitudes of patient safety culture in hospitals $[8,9]$. As shown in Table 1, the SAQ has six dimension and thirty questions, including teamwork climate, safety climate, perceptions of management, job satisfaction, stress recognition, and working conditions. Teamwork climate refers to relationships and cooperation among staffs; safety climate refers to the perceptions of a strong and proactive organizational commitment to safety; job satisfaction reflects the positivity about the work experience; stress recognition is stress factors that link to work performance; perceptions of management describes the approval of managerial actions; working conditions refer to the perceived quality of the work environment and logistical support such as staffing and equipment $[2,10]$.

Table 1 . The safety attitudes questionnaire

\begin{tabular}{|c|c|}
\hline \multirow{6}{*}{$\begin{array}{l}\text { Teamwork } \\
\text { climate }\end{array}$} & (1) Nurse input is well received in this clinical area \\
\hline & $\begin{array}{l}\text { (2) In this clinical area, it is difficult to speak up if I perceive a problem with } \\
\text { patient care }^{(\mathrm{r})}\end{array}$ \\
\hline & $\begin{array}{l}\text { (3) Disagreements in this clinical area are resolved appropriately (i.e. not who } \\
\text { is right, but what is best for the patient) }\end{array}$ \\
\hline & (4) I have the support I need from other personnel to care for patients \\
\hline & $\begin{array}{l}\text { (5) It is easy for personnel here to ask questions when there is something that } \\
\text { they do not understand }\end{array}$ \\
\hline & (6) The physicians and nurses here work together as a well-coordinated team \\
\hline \multirow[t]{7}{*}{ Safety climate } & (7) I would feel safe being treated here as a patient \\
\hline & (8) Medical errors are handled appropriately in this clinical area \\
\hline & $\begin{array}{l}\text { (9) I know the proper channels to direct questions regarding patient safety in } \\
\text { this clinical area }\end{array}$ \\
\hline & (10) I receive appropriate feedback about my performance \\
\hline & (11) In this clinical area, it is difficult to discuss errors ${ }^{(\mathrm{r})}$ \\
\hline & $\begin{array}{l}\text { (12) I am encouraged by my colleagues to report any patient safety concerns I } \\
\text { may have }\end{array}$ \\
\hline & $\begin{array}{l}\text { (13) The culture in this clinical area makes it easy to learn from the errors of } \\
\text { others }\end{array}$ \\
\hline \multirow[t]{5}{*}{ Job satisfaction } & (14) I like my job \\
\hline & (15) Working here is like being part of a large family \\
\hline & (16) This is a good place to work \\
\hline & (17) I am proud to work in this clinical area \\
\hline & (18) Morale in this clinical area is high \\
\hline \multirow{4}{*}{$\begin{array}{l}\text { Stress } \\
\text { recognition }\end{array}$} & (19) When my workload becomes excessive, my performance is impaired \\
\hline & (20) I am less effective at work when fatigued \\
\hline & $\begin{array}{l}\text { (21) I am more likely to make errors in tense or hostile situations (e.g. } \\
\text { emergency resuscitation, seizure) }\end{array}$ \\
\hline & (22) Fatigue impairs my performance during emergency situations \\
\hline \multirow{4}{*}{$\begin{array}{l}\text { Perceptions of } \\
\text { management }\end{array}$} & (23) Managers supports my daily efforts \\
\hline & (24) Managers do not knowingly compromise patient safety \\
\hline & $\begin{array}{l}\text { (25) I get adequate, timely information about events that might affect my } \\
\text { work }\end{array}$ \\
\hline & $\begin{array}{l}\text { (26) The levels of staffing in this clinical area are sufficient to handle the } \\
\text { number of patients }\end{array}$ \\
\hline \multirow{4}{*}{$\begin{array}{l}\text { Working } \\
\text { conditions }\end{array}$} & (27) Problem personnel are dealt with constructively \\
\hline & (28) This hospital does a good job of training new personnel \\
\hline & $\begin{array}{l}\text { (29) All the necessary information for diagnostic and therapeutic decisions is } \\
\text { routinely available to me }\end{array}$ \\
\hline & (30) Trainees in my discipline are adequately supervised \\
\hline
\end{tabular}

Note: r: reversed question 


\section{Methodology}

The nurses were selected as subject via sending a survey at a Grade III Level A hospital in Wuhan City, China in 2017. The hospital contains more than 40 divisions, has 2280 total staff members, 2200 hospital beds, and provides clinical education and training to health professionals. Sexton et al. [7]'s SAQ questionnaire were used to measure patient safety culture. Six dimensions and 30 items were conducted on five-point Likert-type scale, where 1 and 5 respectively represent strongly disagree and strongly agree. Participants were asked to submit the survey in this case hospital. A total of valid 168 questionnaires collected with convenience sampling was used for the analysis. After screening the data, Pearson's correlation analysis was used to confirm the strength and direction of the relationships among six dimensions of patient safety culture.

\section{Results}

\section{Sample Characteristics}

The results of statistical analysis demonstrated that most respondents were female (78.9 percent), the age ranging from 21 to 30 years (68.4 percent), and were educated at the bachelor's level ( 92.4 percent). Additionally, the characteristics revealed that respondents with relevant working experiences were more than five years in the hospital (49.6 percent).

\section{Empirical Results}

As shown in Table 2 safety climate (4.12) and working conditions (4.12) had the highest average values whereas stress recognition (2.66) had the lowest average value. The Cronbach's $\alpha$ values of six patient safety culture dimensions were greater than 0.7 , which indicated an acceptable internal consistency [11].

Table 2. Statistical value and Cronbach's alpha coefficient for nurses $(\mathrm{n}=168)$

\begin{tabular}{|l|l|l|l|l|}
\hline Dimensions & Mean & SD & Item & Cronbach's alpha \\
\hline Teamwork climate & 4.13 & .597 & 7 & .751 \\
\hline Safety climate & 4.16 & .501 & 6 & .745 \\
\hline Job satisfaction & 4.05 & .724 & 5 & .914 \\
\hline Stress recognition & 2.68 & .984 & 4 & .896 \\
\hline $\begin{array}{l}\text { Perceptions of } \\
\text { management }\end{array}$ & 4.16 & .548 & $3 *$ & .702 \\
\hline Working conditions & 4.15 & .478 & 4 & .745 \\
\hline
\end{tabular}

Note: *one item was deleted

Moreover, the results of Pearson correlation analysis in Table 3 stated that working conditions was highly significantly related to perceptions of management $(r=.702, p<0.01)$, safety climate $(r=.635$, $p<0.01)$ and job satisfaction $(r=.631, p<0.01)$, respectively. Safety climate was highly related to teamwork climate $(r=.712, \mathrm{p}<0.01)$ and job satisfaction $(r=.609, p<0.01)$. On the other hand, stress recognition had no significant impact on the rest of five dimensions of patient safety culture.

Table 3. Pearson's correlation analysis for nurses $(n=168)$

\begin{tabular}{|l|l|l|l|l|l|l|}
\hline & 1 & 2 & 3 & 4 & 5 & 6 \\
\hline $1 . \mathrm{TC}$ & & & & & & \\
\hline $2 . \mathrm{SC}$ & $.712^{* *}$ & & & & & \\
\hline $3 . \mathrm{JS}$ & $.530^{* *}$ & $.609 * *$ & & & & \\
\hline $4 . \mathrm{SR}$ & .032 & .068 & $.192^{* *}$ & & & \\
\hline $5 . \mathrm{PM}$ & $.550^{* *}$ & $.602 * *$ & $.594 * *$ & .124 & & \\
\hline $6 . \mathrm{WC}$ & $.493 * *$ & $.635^{* *}$ & $.631^{* *}$ & $.167 * *$ & $.702 * *$ & \\
\hline
\end{tabular}

Note:* $p$-value $<0.05 ; * * p$-value < 0.01 ; TC: teamwork climate; SC: safety climate; JS: job satisfaction; SR: stress recognition; PM: perceptions of management; WC: working conditions 


\section{Conclusions}

Patient safety culture has become an issue globally especially in healthcare industry. The current study aims to investigate the perceptions of nurses toward patient safety culture by surveying the SAQ in a Grade III Level A hospital in China. Overall, the results indicate that nurses are satisfied with the establishment of patient safety culture in a case hospital. Our results demonstrate that working conditions are essential components to establish a good atmosphere of patent-oriented medical service. A better working environment is suggested as an effective way to motivate nurses to work more seriously and treat patient considerately. Besides, hospital management should not ignore the effect of stress on nurses during the medical procedures. Nurses normally stated higher stress and challenges which result from complex and multi-task working situations in the hospital. Stress management implements such as concert, psychological counseling services, and social gathering are suggested to release the pressure for nurses.

\section{Acknowledgement}

This study was supported by Hubei University of Economics with the grant number of XJ16BS34 and Institute for Development of Cross-Strait Small and Medium Enterprise with the grant number of HX1740.

\section{References}

[1] Y.C. Lee, J.I. Shieh, C.H. Huang, C.Y. Wang, H.H. Wu, Analyzing patient safety culture from viewpoints of physicians and nurses: A case of a regional teaching hospital in Taiwan, J. Healthc. Qual. 39 (2017) 294-306.

[2] C.H. Huang, H.H. Wu, Y.C. Lee, The perceptions of patient safety culture: A difference between physicians and nurses in Taiwan, Appl. Nurs. Res. 40 (2018) 39-44.

[3] Lee, Y. C., Huang, S. C., Huang, C. H., \& Wu, H. H. (2016). A new approach to identify high burnout medical staffs by kernel k-means cluster analysis in a regional teaching hospital in Taiwan. Inquiry J. Health Car. 53 (2016) 0046958016679306.

[4] European Union Network for Quality in Health Care. Use of patient safety culture instrument and recommendations. Office for Quality Indicators (2006) Information on http://www.pasq.eu/DesktopModules/BlinkQuestionnaires/QFiles/448_WP4_REPORT\%20\%20Use\% 20of\%20\%20PSCI\%20and\%20recommandations\%20-\%20March\%20\%202010.pdf

[5] M. Danielsson, P. Nilsen, A. Öhrn, H. Rutberg, J. Fock, S. Carlfjord, Patient safety subcultures among registered nurses and nurse assistants in Swedish hospital care: a qualitative study, BMC Nurs. 13 (2014) 39.

[6] Y.C. Lee, P.S. Zeng, C.H. Huang, H.H. Wu, Causal relationship analysis of the patient safety culture based on safety attitudes questionnaire in Taiwan. J. Healthc. Eng. (2018).

[7] J.B. Sexton, R.L. Helmreich, T.B. Neilands, K. Rowan, K. Vella, J. Boyden, P.R. Roberts, E.J. Thomas, The safety attitudes questionnaire: Psychometric properties, benchmarking data, and emerging research, BMC Health Serv Res. 6 (2006) 44.

[8] G. Nguyen, N. Gambashidze, S.A. Ilyas, D. Pascu, Validation of the safety attitudes questionnaire (short form 2006) in Italian in hospitals in the northeast of Italy, BMC Health Serv. Res. 15 (2015) 284.

[9] A. Gabrani, A. Hoxha, A. Simaku, J.C. Gabrani, Application of the safety attitudes questionnaire (SAQ) in Albanian hospitals: a cross-sectional study, BMJ Open. 5 (2015) e006528.

[10]Y.C. Lee, H.H. Wu, W.L. Hsieh, S.J. Weng, L.P. Hsieh, C.H. Huang Applying importance-performance analysis to patient safety culture, Int. J. Health Care Qual. Assur. 28 (2015) 826-840. 
[11] J. Cohen, P. Cohen, S.G. West, L.S. Aiken, Applied multiple regression/correlation analysis for the behavioral sciences, Lawrence Erlbaum Associates, London, 2013. 